\title{
Quality of life and persisting symptoms in intensive care unit survivors: implications for care after discharge Fiona J Baldwin*†, Denise Hinge ${ }^{\dagger}$, Joanna Dorsett ${ }^{\dagger}$ and Owen F Boyd ${ }^{\dagger}$
}

Address: Intensive Care Unit, Royal Sussex County Hospital, Eastern Road, Brighton, UK

Email: Fiona J Baldwin* - fiona.baldwin@bsuh.nhs.uk; Denise Hinge - denise.hinge@bsuh.nhs.uk; Joanna Dorsett - podorsett@doctors.org.uk; Owen F Boyd - owen.boyd@bsuh.nhs.uk

* Corresponding author †Equal contributors

Published: 12 August 2009

BMC Research Notes 2009, 2:160 doi:10.1/86/1756-0500-2-160
Received: 8 June 2009

Accepted: 12 August 2009

This article is available from: http://www.biomedcentral.com/I756-0500/2/160

(C) 2009 Baldwin et al; licensee BioMed Central Ltd.

This is an Open Access article distributed under the terms of the Creative Commons Attribution License (http://creativecommons.org/licenses/by/2.0), which permits unrestricted use, distribution, and reproduction in any medium, provided the original work is properly cited.

\begin{abstract}
Background: We assessed the quality of life of ICU survivors using SF-36 at 4 months after ICU discharge and investigated any correlation of PCS and MCS with age, illness severity and hospital or ICU length of stay. We examined the relationship between these variables, persisting physical and psychological symptoms and the perceived benefit of individual patients of follow-up.
\end{abstract}

Findings: For one year, adult patients admitted for multiple organ or advanced respiratory support for greater than 48 hours to a 16-bedded teaching hospital general intensive care unit were identified. Those surviving to discharge were sent a questionnaire at 4 months following ICU discharge assessing quality of life and persisting symptoms. Demographic, length of stay and illness severity data were recorded. Higher or lower scores were divided at the median value. A twotailed Students t-test assuming equal variances was used for normally-distributed data and MannWhitney tests for non-parametric data.

87 of 175 questionnaires were returned (50\%), but only 65 had sufficient data giving a final response rate of $37 \%$. Elderly patients had increased MCS as compared with younger patients. The PCS was inversely related to hospital LOS. There was a significant correlation between the presence of psychological and physical symptoms and desire for follow-up.

Conclusion: Younger age and prolonged hospital stay are associated with lower mental or physical quality of life and may be targets for rehabilitation. Patients with persisting symptoms at 4 months view follow-up as beneficial and a simple screening questionnaire may identify those likely to attend outpatient services.

\section{Background}

It is increasingly recognised that intensive care unit (ICU) survivors may have a reduction in quality of life $[1,2]$.

Follow-up of survivors of ICU treatment has shown many patients suffer long-term physical and psychological consequences [3-5], although the prevalence of these symp- toms and the role of rehabilitation services remains unclear.

Health-related quality of life (HRQOL) is a state of physical, mental and social wellbeing which is used in assessment of the longer term consequences of treatment [1]. There is no HRQOL score specific to the ICU population 
but a number of general scores have been evaluated [6,7]. Studies assessing HRQOL after intensive care have suggested it is reduced both in comparison to before admission [8-10] and in comparison to the general population $[11,12]$, although it improves with time $[8,10]$.

Studies assessing factors predicting a lower HRQOL following ICU admission, have generated more mixed results [6], which may represent the heterogeneity of both study groups and assessment tools used in ICU outcome research.

We assessed the quality of life of general ICU survivors using the Short Form 36 (SF-36) at 4 months post ICU discharge and investigated any correlation with age, illness severity and hospital or ICU length of stay. We wished to investigate any predictors of low HRQOL scores and identify patients who would potentially benefit from a follow up clinic.

SF-36 is a generic QOL instrument so we supplemented the questionnaire with further enquiries about persisting physical and psychological symptoms which were generated by a combination of literature review and local interest $[5,13]$. Aware of the high nonattendance rates at ICU clinics [14], we also asked patients to rate the perceived usefulness to them of the introduction of a follow-up service at our institution and investigated any relationship with persisting symptoms or SF 36-derived variables.

\section{Methods}

The study was approved by Brighton and Mid Sussex Local Research Ethics Committee (MS 03/28). From November 2004 to October 2005 all adult patients admitted for multiple organ or advanced respiratory support for a period of greater than 48 hours to a 16-bedded university teaching hospital general intensive care unit were identified.

Patients surviving to ICU discharge were approached for verbal consent to participate in the study by a member of the Critical Care team and presented with an information sheet describing the study. We excluded all patients from outside the local area for whom we were unable to check for death after hospital discharge in order to avoid distress to next of kin and patients transferred from or to other ICUs.

We recorded standard demographic data for all ICU patients admitted for the period as well as illness severity (APACHE II score) [15], ICU length of stay (LOS), hospital LOS, mortality status and readmissions to ICU or hospital. Readmission was defined as a return to either hospital or the ICU having previously been discharged at any time during the four month period of the study. This was to identify patients less able to participate in the study. ICU and hospital LOS were calculated as days spent either on ICU or in an acute hospital. ICU LOS was not included in hospital LOS.

We posted a questionnaire to all participants four months after ICU discharge. The questionnaire incorporated both the SF36 (with permission of QualityMetric Incorporated, Lincoln, USA) and questions about persisting symptoms and desire for a local follow-up clinic. Patients were asked "Have you suffered from any of the following in the previous month?" The symptom list consisted of swallowing difficulties; loss of hearing; distressing memories popping into your mind; sleep difficulties; poor concentration; mood changes; weight loss. The patients were given no details about potential follow-up services.

There is consensus that the SF-36 is one of two instruments suited for measuring quality of life after critical care [1]. The SF-36 yields an 8-scale profile of functional health and well-being scores as well as psychometrically-based physical and mental health summary measures [16].

The SF-36 has demonstrated reliability and validity the critically ill $[12,17]$ and the physical (PCS) and mental component summary (MCS) scores relating to quality of life have been used to summarise findings in longitudinal studies of mixed population ICU survivors $[5,8,18]$.

The patients were provided with a stamped, self-addressed envelope in which to return the questionnaire. The questionnaire was piloted on 22 patients and these patients were not included in the final analysis.

Calculation of the SF-36 PCS and MCS scores were in accordance with standard techniques and using QualityMetric software to transform results to "norm based data". This adapts the data to show 50 as population mean and 10 representing one standard deviation [19].

\section{Statistical analysis}

Results from the SF-36 were compared between the patients with the higher scores and those with the lower scores for the discriminator: age, APACHE II score, length of ICU stay (days), and hospital LOS (days). Higher or lower scores were divided at the median value. A two sample, two-tailed Students t-test assuming equal variances was used, $\mathrm{p}<0.05$ was considered significant $\left({ }^{*}\right)$. Results were compared between the lower $50 \%$ and higher $50 \%$ of patients for each discriminator.

The perceived benefit of follow up services was rated according to a five point scale (Table 1) and groups with or without persisting symptoms compared using the Mann-Whitney test converted to 2-tailed $\mathrm{p}$ value. 


\section{Results}

363 patients required multiple organ or advanced respiratory support with length of stay $>48$ hours during the study period and of these 219 survived to 4 months following ICU discharge. 175 had returned home 4 months after ICU discharge. 87 questionnaires were returned with some data giving a response rate of $50 \%$. The entire 175 were analyzed to explore the differences between the patients who responded to the questionnaire as compared to the non-responders (Table 2). Only 65 questionnaires had sufficient data to allow calculation of MCS and PCS scores which gives a response rate of $37 \%$ for summary score data (Table 3). Elderly patients had increased mental component summary as compared with younger patients. The physical component summary was inversely related to hospital LOS.

The desire for a follow-up service was rated on a 5-point scoring system and was completed by 83 patients (47\%). There was no correlation between the perceived benefit of follow up services and demographic variables, illness severity or LOS, PCS, MCS or PCS and MCS combined.

The persistence of symptoms in our population is illustrated in Figure 1. These symptoms were divided into psychological (distressing memories, sleep difficulties, poor concentration and mood changes) and physical groupings (dysphagia, weight loss and loss of hearing) in an attempt to mirror the PCS and MCS broad categorizations.

There was a highly statistically significant relationship between the presence of either physical symptoms or psychological symptoms and the desire for follow-up (Figures 2 and 3 ).

\section{Discussion}

Our study showed that elderly ICU survivors, after ICU discharge, demonstrated a statistically significant differ-

Table I: Responses to: "How beneficial do you think a follow-up service would have been to you?"

\begin{tabular}{ccc}
\hline Response & Score rating & $\begin{array}{c}\text { All patients } \\
\mathbf{n}=\mathbf{8 3}\end{array}$ \\
\hline Not at all & 1 & 8 \\
\hline A little & 2 & 13 \\
\hline Moderately & 3 & 14 \\
\hline Quite a bit & 4 & 23 \\
\hline Extremely & 5 & 25 \\
\hline
\end{tabular}

83 out of 87 patients responded to this question. ence in the MCS of the SF-36 to younger patients. This positive mental health attitude has been shown by others, but only in sub domains of the SF-36 or specifically in men $[8,11,20,21]$. This finding of a more positive mental component summary in older patients may have several explanations. It may represent a difference in reason for ICU admission. Studies have shown that HRQOL scores are similar before and after ICU for patients with pre-existing ill-health, while patients suffering sudden and acute pathologies have a marked reduction in score $[12,22]$. Our results may represent the fact that there are a greater proportion of younger patients in the second category.

A second explanation may be that older patients are better able to cope with the consequences of surviving critical illness than younger people. The similarity in PCS between the two groups would support this. Our study suggests that there may be differing expectations and willingness to accept physical limitations between older and younger patients.

We demonstrated a correlation between hospital length of stay and the physical component summary of the SF 36, the PCS. As Hospital LOS was calculated following discharge from ICU this would represent patients with a prolonged recovery and was expected as physical weakness inevitably impacts on ability to leave hospital. There is also a recognized relationship in ICU survivors between hospital LOS and subsequent development of chronic pain as chronic pain is associated with a poorer HRQOL [20]. Trauma patients, who are often younger, are also known to have prolonged hospital stay on the general ward [23].

We did not demonstrate a correlation between APACHE II scoring and PCS or MCS in ICU survivors. This is consistent with other authors who looked directly at this relationship [5,8].

We assessed other morbidities of interest to us using a series of short questions added to the SF-36 tool as previously advocated [1]. The results demonstrate a large amount of psychological morbidity, a finding consistent with other UK investigators $[5,24,25]$. The positive correlation between specific ICU-related symptoms and the perceived benefit of a follow-up clinic was marked and although the usefulness of individual symptoms is debatable, that patients with persisting symptoms attributable to ICU stay are more likely to feel follow-up services are beneficial may be useful in screening patients likely to use rehabilitation facilities.

\section{Strengths and Limitations of the Study}

The strength of our study was our attempt to identify a pure general ICU population, using requirement for mul- 
Table 2: Differences between patients responding and not responding to the questionnaire sent to them

\begin{tabular}{llll}
\hline & All Responders & Full data Responders & All Non-responders \\
\hline Number & 87 & 65 & 88 \\
\hline Age (median years) & $66(55-73)$ & $63(53-73)$ & $59(4 I-71)$ \\
\hline Sex & $32 \%$ Female & $29 \%$ Female & $34 \%$ Female \\
\hline APACHE II (median) & $18(15-24)$ & $17(14-22)$ & $17(12-20)$ \\
\hline ICU length of stay (median days) & $8(3-16)$ & $8(3-14)$ & $5(3-12)$ \\
\hline Hospital length of stay (median days) & $25(15-48)$ & $25(14-47)$ & $24(14-36)$ \\
\hline Hospital readmission rate & $24 \%$ & $26 \%$ & $34 \%$ \\
\hline ICU readmission rate & $3.5 \%$ & $4.6 \%$ & $10 \%$
\end{tabular}

Characteristics of both groups of responders described; all responders including those with partial data and full responders defined as those with sufficient data to allow PCS and MCS to be calculated. Interquartile range in brackets.

tiple organ or advanced respiratory support and LOS $>48$ hours.

The largest limitation of our study is the response, with a questionnaire return rate of approximately $50 \%$. Although consistent with previous studies using a postal self-administered technique $[20,26]$ it is less than studies using SF 36 administered by other methods $[8,11]$.

The number of patients unable to fully complete the questionnaire was also disappointing providing a response rate for PCS and MCS data of only $37 \%$.

Aware of the potential for selection bias as a result of the low response rate, we looked for differences between the patients responding or not to the questionnaire. The differences in both hospital and ICU readmission rates suggest that the non responders may have still been in hospital or only recently discharged. The fact that the nonresponders were younger is not necessarily surprising, but younger and sicker less easy to explain.

The readmission rate to hospital within four months of the ICU survivors was higher than expected [27]. 70\% of admissions were related to the primary ICU admission.

In retrospect, the prospective categorization of symptoms into physical and psychological, whilst influenced by SF36 PCS and MCS, was confusing and open to criticism. If the results had been analysed using simply persisting symptoms vs. perceived benefit of clinic they would have been more statistically significant (Mann-Whitney 2tailed $\mathrm{p}<0.002)$.

We have used norm based data from a US population to calculate the physical and mental health summary scores.

Table 3: MCS and PCS relationship to discriminators of age, length of stay and illness severity.

\begin{tabular}{llllll}
\hline & Discriminator & Age (years) & $\begin{array}{l}\text { Hospital length of stay } \\
\text { (days) }\end{array}$ & $\begin{array}{l}\text { ICU length of stay } \\
\text { (days) }\end{array}$ & APACHE II \\
\hline MCS & Mean below median value & $39.32 *(14.3)$ & $44.99(14.7)$ & $42.12(15.2)$ & $44.04(16.2)$ \\
\cline { 2 - 5 } & Mean above median value & $46.78(14.7)$ & $41.28(15.1)$ & $44.07(14.8)$ & $42.21(13.7)$ \\
\hline PCS & \begin{tabular}{l} 
Mean below median value \\
\cline { 2 - 5 }
\end{tabular} & $35.04(11.7)$ & 39.3 I $*(12.8)$ & $36.08(11.9)$ & $35.85(12.1)$ \\
\hline
\end{tabular}

Relationship defined by the median of each variable in the responder patients (see Table 2). Standard deviations given in brackets. Patients above median age show improved SF-36 mental component scores. Patients above hospital median LOS have lower physical component scores. ${ }^{*}$ indicates statistical significance 2-tailed Student's t-test $<0.05$. See text) 


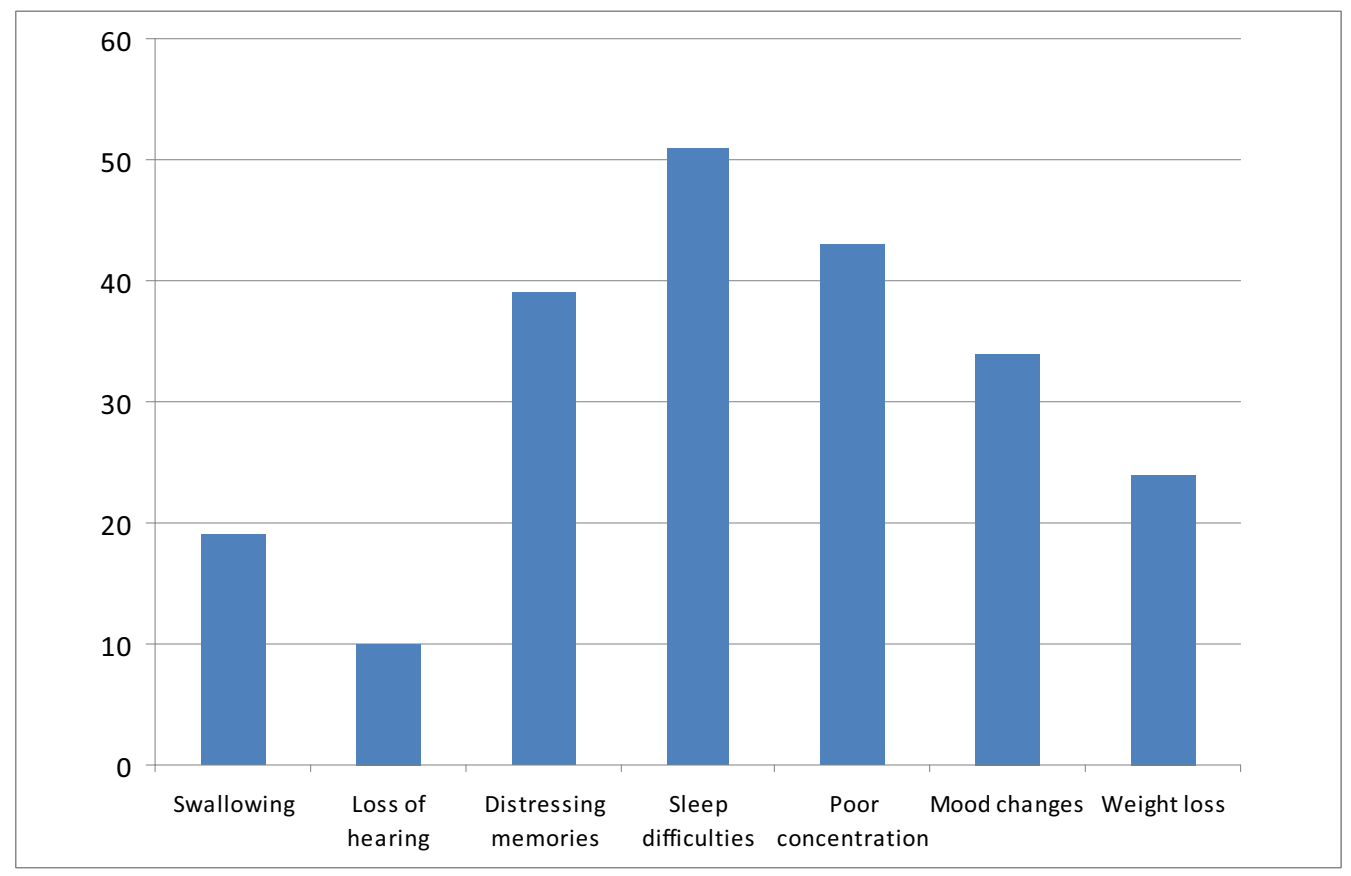

\section{Figure I}

Persisting symptoms related to ICU admission at $\mathbf{4}$ months. The number of patients having persisting symptoms as described in Methods in the previous I month. Many patients had more than one symptom.

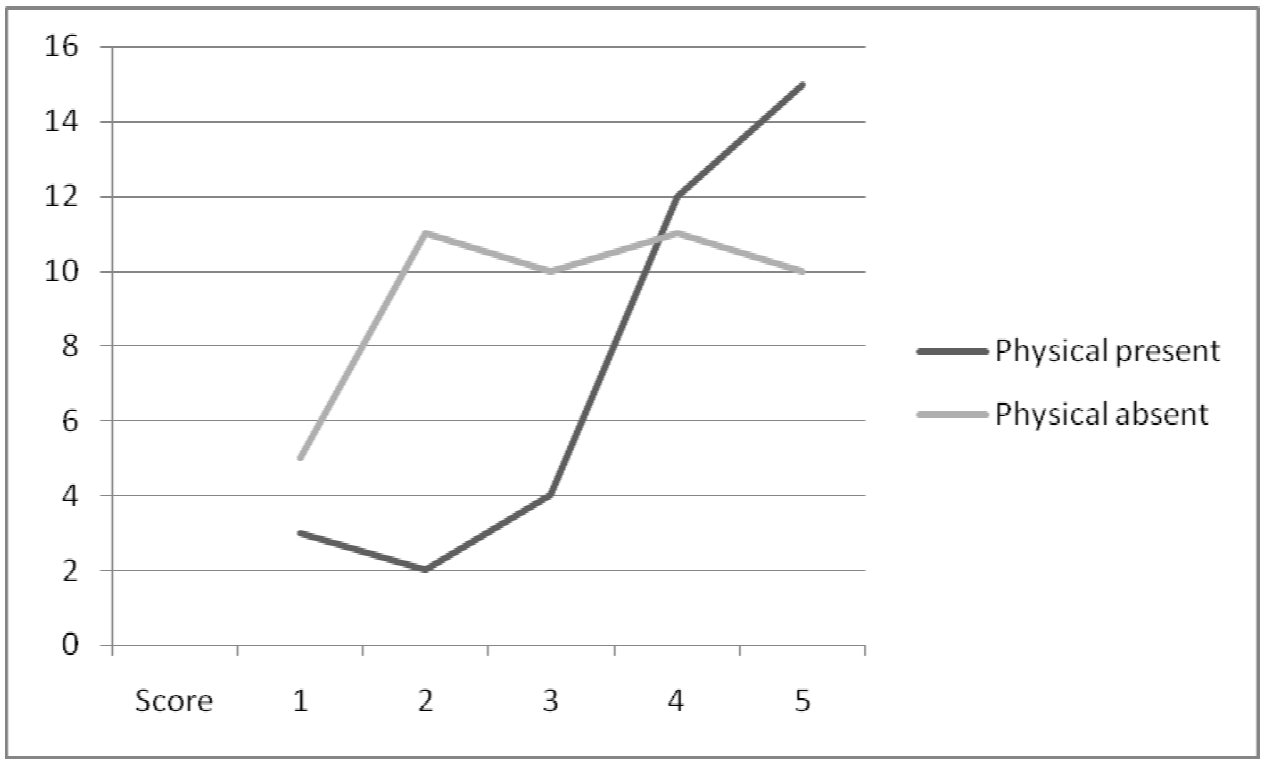

\section{Figure 2}

Follow-up and physical symptoms. Score of perceived usefulness of follow-up services vs. number of patients describing physical symptoms in the previous month. Patients with symptoms are more likely to perceive follow-up services as beneficial (Mann-Whitney test 2 tailed $\mathrm{p}<0.01 *(0.0094)$ ). 


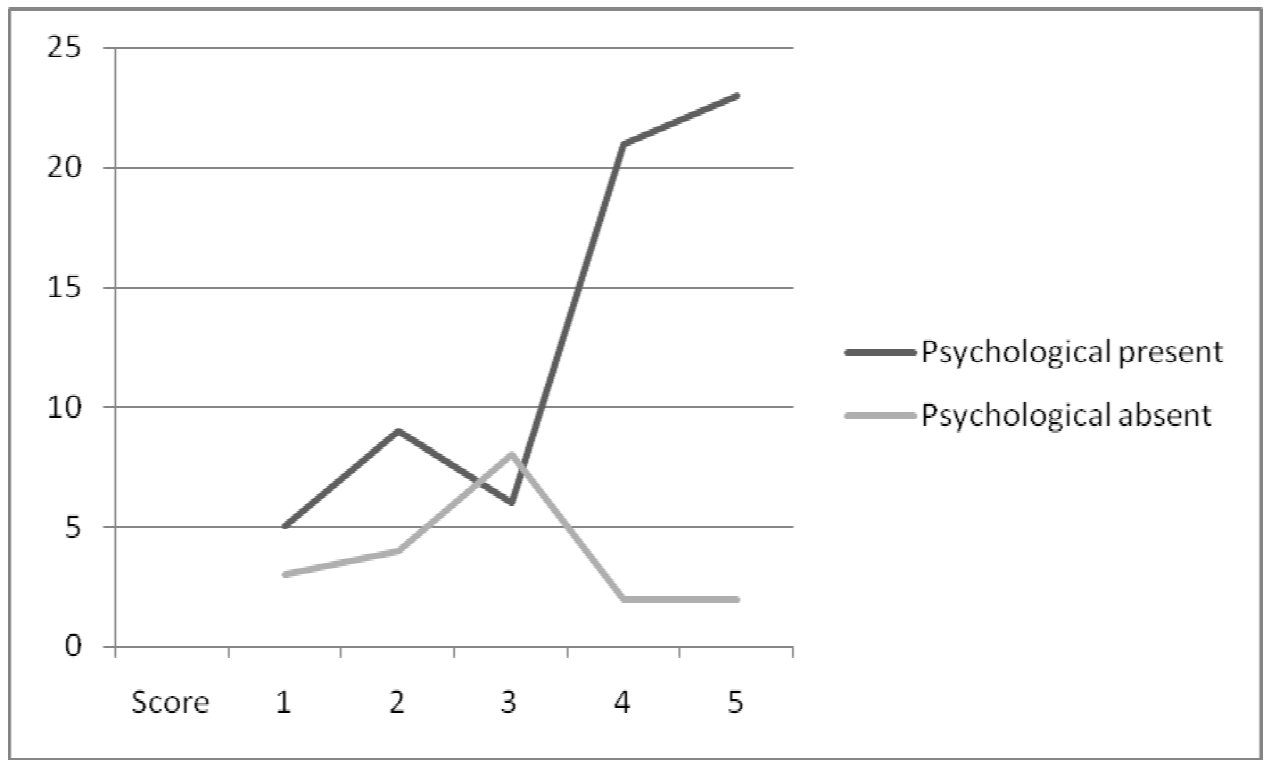

\section{Figure 3}

Follow-up and psychological symptoms. Score of perceived usefulness of follow-up services vs. number of patients describing psychological symptoms in the previous month. Patients with symptoms are more likely to perceive follow-up services as beneficial (Mann-Whitney test 2-tailed $p<0.01 *(0.0036)$ ).

There is limited normative data for the SF-36 on the UK population over 64 and caution has been counseled in its use [28].

Four months may be considered a short survey time for critically ill patients with prolonged ICU stay, the recommendation is 6-12 months [1] and we may have gained more by assessing pre-admission QOL from relatives as previously described [8].

Our study was in a single centre and so may not be generally applicable.

\section{Conclusion}

At 4 months after ICU discharge, the more elderly have significantly better psychological HRQOL as compared with younger patients. Prolonged hospital LOS is associated with a significant reduction in the physical domains of HRQOL. There is a demand for follow-up services and it is related to persisting symptoms at four months identified using a simple questionnaire. The use of a questionnaire to screen patients may identify those likely to attend and needs to be evaluated more fully. Younger patients and those with prolonged hospital lengths of stay have lower quality of life indices and this may have implications for rehabilitation services.

\section{Abbreviations}

ICU: Intensive Care Unit; HRQOL: Health-related quality of life; SF-36: Short Form 36; MCS: Mental component summary of the SF-36; PCS: Physical component summary of the SF-36; LOS: Length of stay.

\section{Competing interests}

The authors declare that they have no competing interests.

\section{Authors' contributions}

FJB designed the study and produced the manuscript. DH assisted in the design of the study and data collection. OFB assisted with study design, performed statistical analysis and on revision of the manuscript. PD assisted with data analysis. All authors read and approved the final manuscript.

\section{Acknowledgements}

We would like to acknowledge the contributions of Helen Goldman, Sarah Goodhew and Sarah Dibb-Fuller in helping with data collection.

We would also like to thank the Research and Development Department of the Brighton and Sussex University Hospitals NHS Trust for funding the project.

\section{References}

I. Angus DC, Carlet J: Surviving intensive care: a report from the 2002 Brussels Roundtable. Intensive Care Med 2003, 29(3):368-377.

2. Rubenfeld GD, Angus DC, Pinsky MR, Curtis JR, Connors AF Jr, Bernard GR: Outcomes research in critical care: results of the American Thoracic Society Critical Care Assembly Work- 
shop on Outcomes Research. The Members of the Outcomes Research Workshop. Am J Respir Crit Care Med 1999, I 60(I):358-367.

3. Broomhead LR, Brett S]: Clinical review: Intensive care followup - what has it told us? Crit Care 2002, 6(5):4III-4I7.

4. Jackson JC, Hart RP, Gordon SM, Hopkins RO, Girard TD, Ely EW: Post-traumatic stress disorder and post-traumatic stress symptoms following critical illness in medical intensive care unit patients: assessing the magnitude of the problem. Crit Care 2007, I I (I):R27.

5. Sukantarat K, Greer S, Brett S, Williamson R: Physical and psychological sequelae of critical illness. Br J Health Psychol 2007, I 2(Pt I):65-74.

6. Dowdy DW, Eid MP, Sedrakyan A, Mendez-Tellez PA, Pronovost PJ, Herridge MS, Needham DM: Quality of life in adult survivors of critical illness: a systematic review of the literature. Intensive Care Med 2005, 3 I(5):6 I I-620.

7. Cheung AM, Tansey CM, Tomlinson G, Diaz-Granados N, Matte A Barr A, Mehta S, Mazer CD, Guest CB, Stewart TE, et al.: Two-year outcomes, health care use, and costs of survivors of acute respiratory distress syndrome. Am J Respir Crit Care Med 2006 174(5):538-544.

8. Cuthbertson BH, Scott J, Strachan M, Kilonzo M, Vale L. Quality of life before and after intensive care. Anaesthesia 2005, 60(4):332-339.

9. Graf J, Koch M, Dujardin R, Kersten A, Janssens U: Health-related quality of life before, I month after, and 9 months after intensive care in medical cardiovascular and pulmonary patients. Crit Care Med 2003, 3 I (8):2163-2169.

10. Hofhuis JG, Spronk PE, van Stel HF, Schrijvers GJ, Rommes JH, Bakker J: The impact of critical illness on perceived health-related quality of life during ICU treatment, hospital stay, and after hospital discharge: a long-term follow-up study. Chest 2008, I33(2):377-385.

II. Eddleston JM, White P, Guthrie E: Survival, morbidity, and quality of life after discharge from intensive care. Crit Care Med 2000, 28(7):2293-2299.

12. Ridley SA, Chrispin PS, Scotton H, Rogers J, Lloyd D: Changes in quality of life after intensive care: comparison with normal data. Anaesthesia 1997, 52(3):195-202.

13. Jones C, Skirrow P, Griffiths RD, Humphris GH, Ingleby S, Eddleston J, Waldmann C, Gager M: Rehabilitation after critical illness: a randomized, controlled trial. Crit Care Med 2003, $3 I(10): 2456-246 I$.

14. Williams TA, Leslie GD: Beyond the walls: a review of ICU clinics and their impact on patient outcomes after leaving hospital. Aust Crit Care 2008, 21(1):6-17.

15. Knaus WA, Draper EA, Wagner DP, Zimmerman JE: APACHE II: a severity of disease classification system. Crit Care Med 1985, I3(10):818-829

16. Ware JE Jr, Kosinski M, Bayliss MS, McHorney CA, Rogers WH, Raczek A: Comparison of methods for the scoring and statistical analysis of SF-36 health profile and summary measures: summary of results from the Medical Outcomes Study. Med Care 1995, 33(4 Suppl):AS264-279.

17. Chrispin PS, Scotton H, Rogers J, Lloyd D, Ridley SA: Short Form 36 in the intensive care unit: assessment of acceptability, reliability and validity of the questionnaire. Anaesthesia 1997 52(I):15-23.

18. Hofhuis JG, Spronk PE, van Stel HF, Schrijvers AJ, Bakker J: Quality of life before intensive care unit admission is a predictor of survival. Crit Care 2007, I I(4):R78.

19. Ware JE, Koninski M, Dewey JE: How to score version 2 of the SF-36 Health Survey Lincoln RI: QualityMetric Inc; 2000

20. Boyle M, Murgo M, Adamson H, Gill J, Elliott D, Crawford M: The effect of chronic pain on health related quality of life amongst intensive care survivors. Aust Crit Care 2004, 17(3): 104-106. 108-113

21. Abelha FJ, Santos CC, Maia PC, Castro MA, Barros H: Quality of life after stay in surgical intensive care unit. BMC Anesthesiol 2007, 7:8.

22. Wehler M, Geise A, Hadzionerovic D, Aljukic E, Reulbach U, Hahn EG, Strauss R: Health-related quality of life of patients with multiple organ dysfunction: individual changes and comparison with normative population. Crit Care Med 2003, 3 I(4): | $094-|10|$.
23. Korosec Jagodic $\mathrm{H}$, Jagodic K, Podbregar M: Long-term outcome and quality of life of patients treated in surgical intensive care: a comparison between sepsis and trauma. Crit Care 2006, I0(5):RI34.

24. Scragg $\mathrm{P}$, Jones $\mathrm{A}$, Fauvel $\mathrm{N}$ : Psychological problems following ICU treatment. Anaesthesia 200I, 56(I):9-14.

25. Jones C, Griffiths RD, Humphris G, Skirrow PM: Memory, delusions, and the development of acute posttraumatic stress disorder-related symptoms after intensive care. Crit Care Med 200I, 29(3):573-580.

26. Deja M, Denke C, Weber-Carstens S, Schroder J, Pille CE, Hokema F, Falke KJ, Kaisers U: Social support during intensive care unit stay might improve mental impairment and consequently health-related quality of life in survivors of severe acute respiratory distress syndrome. Crit Care 2006, I0(5):RI47.

27. Keenan SP, Dodek P, Chan K, Simon M, Hogg RS, Anis AH, Spinelli JJ, Tilley J, Norena M, Wong H: Intensive care unit survivors have fewer hospital readmissions and readmission days than other hospitalized patients in British Columbia. Crit Care Med 2004, 32(2):391-398.

28. Brazier JE, Harper R, Jones NM, O'Cathain A, Thomas KJ, Usherwood $T$, Westlake L: Validating the SF-36 health survey questionnaire: new outcome measure for primary care. BM] [992, 305(6846): 160-164.
Publish with Bio Med Central and every scientist can read your work free of charge

"BioMed Central will be the most significant development for disseminating the results of biomedical research in our lifetime. "

Sir Paul Nurse, Cancer Research UK

Your research papers will be:

- available free of charge to the entire biomedical community

- peer reviewed and published immediately upon acceptance

- cited in PubMed and archived on PubMed Central

- yours - you keep the copyright
BioMedcentral 